\title{
Troubled Relationships in Early Childhood Education: Parent-Teacher Interactions in Ethnoculturally Diverse Child Care Settings
}

Judith K. Bernhard

Ryerson University

Marie Louise Lefebvre

Université du Québec à Montréal

Kenise Murphy Kilbride

Ryerson University

\section{Gyda Chud}

Vancouver Community College

\section{Rika Lange}

Vancouver Health Department

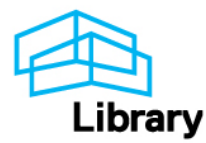




\title{
Troubled Relationships in Early Childhood Education: Parent-Teacher Interactions in Ethnoculturally Diverse Child Care Settings
}

\author{
Judith K. Bernhard \\ Ryerson Polytechnic University \\ Marie Louise Lefebvre \\ Université du Québec à Montréal \\ Kenise Murphy Kilbride \\ Ryerson Polytechnic University \\ Gyda Chud \\ Vancouver Community College \\ Rika Lange \\ Vancouver Health Department
}

\begin{abstract}
In order to study the nature of the relationships between early childhood educators and minority families, we interviewed child care teachers $(N=199)$ and supervisors $(\mathrm{N}=77)$ in three Canadian cities of major immigrant influx. Views of minority families were elicited through 14 focus groups (total attendance, $N=108$ ) in these cities. A coordinated analysis of data revealed four main findings as follows:
\end{abstract}

1) Although both minority parents and teachers agreed that minority parents were not involved enough in the child care setting, they disagreed about the reasons for the lack of involvement. 2) Minority parents and teachers tended to be unaware of their basic differences in ECE goals, particularly with respect to cognition, social skills, and respect for authority; they gave conflicting accounts of difficulties related to these goals. 3) Schools and minority parents appeared to have substantial differences over what constitutes proper child-rearing methods in the home. The practices of minority parents were often viewed by teachers as lax.4) Based on teachers' and parents' reports, racial and discriminatory incidents, according to the various definitions of those involved, were not uncommon in child care centers; sometimes teachers were unaware of them. Subtle and unintended effects of racism were much more noticed by some parents than by many teachers.

Some of these difficulties may be linked to an "expert model" of early childhood education; hence it is proposed that a collaborative approach is one avenue to better relations between teachers and minority parents.

For additional information please contact the first author, Judith K. Bernhard, Ph.D., School of Early Childhood Education, Ryerson Polytechnic University, 350 Victoria St., Toronto, Ontario, Canada, M5B 2K3 (phone: 416-979-5000, ext. 7647; e-mail: jbernhar@acs.ryerson.ca). 


\section{Troubled Relationships in Early Childhood Education: \\ Parent-Teacher Interactions in Ethnoculturally Diverse Child Care Settings}

Under present global migration patterns, we can expect the racial, cultural, and linguistic diversity of the North American population to continue to increase. Children from all continents form substantial minorities in child care populations in the US and Canada. In some cases, the various groups constitute a majority of children in early childhood education (ECE) centers. Hence, ECE centers face a variety of challenges and are called on to respond in new ways. Parent-teacher relationships are important in any educational setting; they are even more critical when parents and teachers come from different cultural and racial backgrounds because the two stakeholder groups are likely to differ in their approaches to child rearing (Okagaki \& Sternberg, 1993). Our basic premise in investigating differences in these relationships is that parents, as well as teachers, want the children to develop well and to succeed in school.

The challenges of ECE in diverse settings are faced by educators in all nations which have substantial rates of immigration. In the US, the National Association for the Education of Young Children (NAEYC) recently proposed a comprehensive response to diversity (1995), strongly emphasizing relationships between ECE teachers and families. The main recommendation was as follows:

Parents and families should be actively involved in the learning and development of their children. Teachers should actively seek parental involvement and pursue establishing a partnership with children's families... Parents and families should be invited to share, participate, and engage in activities with their children.... Families and parents should be invited to share activities that are developmentally appropriate and meaningful within their culture.... The early childhood educator should ensure that parents are informed and engaged with their child in meaningful activities that promote linkages between the home and the early care setting. (NAEYC, 1995, pp. 8-9)

Clearly, thèse educators see working with families as contributing to positive outcomes for children, especially in the area of retention of family language and culture. Because of the demonstrated correlation between home variables and children's success in school (e.g., Delgado-Gaitan, 1990; Ghazvini \& Readdick, 1994; Goldenberg, 1993; Ramirez \& Douglas, 1989) several Western countries have proposed policies and strategies to promote cooperation between parents and school staff (e.g., in Belgium, Verlot, 1995; in the US, Becher, 1985; Bright, Hidalgo, Siu, \& Swap, 1994; in Canada, Drolet, 1994; Office des services de garde à l'enfance, 1994; Ontario, Ministry of Education and Training, 1994; in Australia, Boston, 1995; in Portugal, Marques, 1995). Such strategies have begun to be implemented but there is little, published large-scale data on the difficulties of implementation or of detailing the interactions of stakeholders.

Parent-teacher relations reflect not only the problems of interaction between different cultural groups but also structural problems based on the present North American system of ECE. Since the beginning, preschools have dealt with issues of socialization, but over the past century, educators' views and practices have undergone substantial development. Fein 
(1980) has noted how, during the first half of the 20th century, nursery schools either detached parents from the school or invited them to come and learn "about proper child rearing" (p. 181). A cooperative approach was less commonly found. Investigators such as Kessler and Swadener (1992), Lubeck (1994), Mallory and New (1994) and Walsh (1991) have called attention to what we will call a standard model for ECE currently followed by most centers in North America: Administrators and teachers are the experts who make the decisions and are charged with the responsibility for informing and educating families of appropriate child rearing strategies. The expert approach, it has been argued, transmits a dominant culture and language to the children and families, and is not normally based on genuine collaboration between equals (Gonzalez-Mena, 1997).

A second aspect of the standard model is the assumption of one universal pattern of proper child-rearing and development. Kessen (1983), and others, have documented the construction of the American child and how the educational system molds children in accord with that unitary construction. The current methods of assessment impute deficiencies to those children who depart from the alleged universal pattern. Elsewhere we have proposed (Bernard, 1995; Bernhard \& Freir, 1996) that there may be multiple and equally valid developmental patterns, and several other investigators have stressed the need for educators to consider pluralism in views of optimal child development (Okagaki \& Sternberg, 1993). In short, to the extent that parents' values are discounted there may be what we would call institutional hindrances to true collaboration between teachers and parents. One way of promoting collaboration arguably is to bring about the institutional reforms indicated in the NAEYC (1995) recommendations.

There have been several general studies indicating particular problems in relationships between ECE teachers and families. For instance, Endsley and Minish (1991) reported mostly short (mean 12 seconds) routine interchanges where parents ask for information (see also Fein, 1980). Parents and teachers have been found to have significant differences in values and expectations regarding the development of children (Robinson, Robinson, Wolins, Bronfenbrenner, \& Richmond, 1973; Sjolund, 1973; West, Hausken, \& Collins, 1993). Parents have been reported to feel coerced, not listened to, and not to have benefited from increased-eontact with the school (Bauch, 1992; Costas, 1991). Parents at child care centers have expressed concerns around "negative child behavior and negative aspects of peer influence" (Pence \& Goelman, 1987, p. 114). Yet much of such data is not broken down by culture and language. Chang's (1993) study is an exception; it addressed the question of how programs may affect the continuing participation of parents in children's education. Based on the data about language barriers in communication with parents, the researchers suggested that "language and cultural barriers between child care providers and parents may be creating feelings of alienation for many language and cultural minority parents" (Chang, 1993, p. 66; see also LaGrange, Clark, \& Munroe, 1994). It is appropriate to duplicate her rigorous and large-scale approach in other areas of North America.

\section{Theoretical Background}

Relationships between ECE teachers and families also reflect wider problems within the social context. The structure of North American society cannot be understood without taking into account subordination of particular cultural and racial groups by the majority culture (Jordan, 1968; Miles, 1989; Ng, 1993; cf. Hall, 1980). Here, subordination is intended 
to refer to all means by which groups become socially disadvantaged through the operation of institutional processes. When teachers and parents interact in what Miles (1989) referred to as "racialized context" (see also James, 1994), one is strongly influenced by the "race" categories in which people construe one another. Thus the outcomes of such encounters are often independent of the good intentions of those involved. We assume that preschool children have the beginnings of racial awareness and knowledge of racial and cultural stereotypes (Crooks, 1970; Johnson, 1977). But even if children were blind to "race," the racial and cultural aspects of their lives are obviously constructed by teachers and parents in particular ways which affect interactions of the children and all other stakeholders. Specifically, teacherparent interactions reflect the perspectives of all stakeholders as to what is occurring in the racialized context of the children's educational environment. There is some evidence that incidents between children are designated as racial in accord with possibly different understandings of toachers and parents; the inference is based on numbers of racial incidents labeled so by parents but apparently not recognized by teachers who are understandably operating from their own perspectives (Derman-Sparks, 1991; James, 1995).

Troyna (1992) has argued that such overt and identifiable incidents are not necessarily the most important manifestations of racism in a given educational system or society (see also Hall, 1980). As a number of studies have reported, teachers, like others in the majority culture, may simply be unaware of racial dimensions of situations where there is no obvious ill-will among those interacting (e.g., James, 1901; Sleeter. 1992; Williams-Shreve, 1992). This may prevent people from appreciating the extent of racism, and understanding the actual experiences of the children and families in the system. Thus it would appear that the ideal way to understand overt as well as subtle "racial" phenomena is to investigate in depth the experiences of substantial numbers of participants, including teachers and parents in a number of representative cities.

\section{Studies of Parents and Teachers in Diverse Child Care Settings}

When ethnocultural groups interact, differences in values, particularly with regard to program content, are an additional source of difficulties in relationships between teachers and parents. Child care settings of minority and poor children were examined by Holloway Rambaud. Fuller and Eggers-Piérola (1995). Avors tharee-year period, 14 low-income mothers were intervieweu auuui surasicalion goals in relation to their presotrool-age children. Some of the mothers believed there were inconsistencies between their goals and those of the schools. School personnel and teacher interviews were not reported. Holloway and her colleagues found that mothers' relationships with teachers were harmed by the teachers' perceived lack of acknowledgment of the parents' goals for the children; they suggested that school personnel and mothers work toward satisfactory mutual accommodation and respect.

Okagaki and Sternberg (1993) studied 359 parents of immigrant children (Filipino, Mexican, and Vietnamese), native-born Anglo-Americans, and native-born MexicanAmericans who had children in kindergarten, first-and second-grade. The immigrant parents believed it was important for their children to learn to conform to external standards and gave equal or greater importance to social as compared to cognitive skills. Teachers were not interviewed. The investigators concluded there were problems in school performance resulting from focus on intellectual assessment deriving from standard Western psychological theory. Parent-teacher relationships would thus be affected to the extent that common foci 
are not agreed upon. The study is provocative, but few other investigators have attempted such fine-grained analysis of substantial samples. There have been no Canadian published data of comparable quality.

Few of the above studies have looked at more than one group of informants: Most have relied solely on either parent or teacher reports. Only a small number have attempted to look at relationship problems from multiple perspectives. Few or no published studies have sought to coordinate data from several sources in order to gain a deeper understanding of these problems. Few have considered both quantitative and qualitative data. It is proposed that without multiple perspectives and types of data, some issues cannot be clarified. Any one perspective, considered on its own, can appear plausible and definitive.

To the extent that larger patterns of disadvantage and subordination of cultural and racial groups are the context of early childhood education, one expects the ECE system to face a number of challenges and difficulties. The micro-interactions of parents and teachers can be expected to be molded by commonly occurring patterns colored by social interaction among cultural and racial groups as well as by institutional characteristics of the ECE system itself. Hence the pursuit of our overall goal - to characterize parent-teacher relationships in diverse contexts - required a complex, multi-stranded approach. It was necessary to listen to many voices. In a larger, three-year project, we investigated relationships between ECE teachers and families through multiple perspectives and three different data sources (supervisors, teachers, parents). The project had three constituent studies, portions of which are more deeply analyzed in the present paper. The studies are labeled Center Study, Family Study, and Faculty Study. The Center Study had two components as described below. The Center Study and Faculty Study had large quantitative portions, and the quantitative data were used to help corroborate and select qualitative themes. The following were the specific research questions of the present study:

1. What is the nature of teacher-family relationships as seen by the teachers and parents with respect to social variables including attitudes toward participation, effectiveness of communication, and cultural and racial sensitivity?

2. How do parents and teachers perceive and work with differences regarding appropriate child care and development values?

3. How are racial incidents constructed and handled by parents and teachers according to their respective views?

In order to address these questions, our research team interviewed teachers and families in the Canadian cities of major immigrant influx: Toronto, Vancouver, and Montreal. This paper, arising from all three studies, addresses one of the major challenges expressed by all respondents: parent-teacher communication in diverse child care centers. The Faculty Study and data are not explicitly considered because ECE faculty members lacked direct involvement in the teacher-parent interactions (see Bernhard, Lefebvre, Chud, \& Lange, 1997). In sum, we present here a coordinated analysis of data from the Center and Family Studies, which were obtained from three sources-supervisors, teachers, and family - to provide a deeper understanding of stakeholders' relationships with each other. It was recognized that, except for the quantitative component of the Center Study dealing with paired minority-majority children, data would not be obtained which would permit direct comparisons of minority 
versus majority persons in the ECE system. Outside the component mentioned, the chosen, non-comparative method was intended to provide an exploratory survey of difficulties in parent-teacher relations in the experience of minority stakeholders. Further, outside the quantitative portion of the Center Study, it was not feasible, on a large scale basis, to obtain rigorously sampled, qualitative data on exactly the same incidents from several sources.

Thus the original three studies permitted a certain amount of triangulation in a strict sense by virtue of wide-scale sampling and quantitative data. But the qualitative data considered here, though shaped by the quantitative findings, did not access the same respondents for specific events and so do not allow triangulation in the strict sense. The present multiple-perspective approach however, does allow preliminary conclusions on commonly occurring types of issues. The question of the kinds of inferences licensed respectively by the three data sources (supervisors, teachers, parents) and by the respective methods of collection is addressed below under Method and Results.

\section{Method}

\section{Data Gathering}

Center Study: Supervisor and teacher interviews. In Component One of the Center Study we interviewed 77 supervisors and 199 teachers at 77 randomly selected group child care centers in Toronto, Montreal, and Vancouver. Supervisors were interviewed by phone in a 15-minute conversation and teachers in person in a one-hour interview. About $30 \%$ of teachers had been in the field for over 10 years; $54 \%$ had less than 7 years experience, and $16 \%$ had between 7 and 10 years of experience. We explored with teachers the benefits and challenges associated with diversity and focused a number of questions on teacher-parent interactions. The sampling method was intended to secure generalizability for the quantitative data as far as teachers and supervisors in these three Canadian cities. The manner of collection of comments, however, would permit only provisional identification of themes and formulation of preliminary conclusions.

Center Study: Minority-majority child pairs. In Component Two of the Center Study we visited 77 randomly chosen centers in three Canadian cities and asked teachers to characterize one pair of children in which one was a child of a minority race or culture and the other a child of the majority race or culture. The labels we used in interviews, respectively, were 'focal' and 'paired' child. (We employ the shorthand terms minority and majority to refer, respectively, to the non-dominant and dominant racial-cultural groups in Canada considered as a whole; for us, the issue of numerical proportions was entirely secondary.) The two children were matched for age and sex. We wished to investigate teachers' differential perceptions of individual strengths and problem areas in order to see how teachers work with the challenge of caring for these two sets of children.

With the interviewer blind to the actual selection process and names of the two children, supervisors were asked randomly to select one minority-majority pair from the register of children who had been in the center for at least six months, according to the following procedure: Supervisors pooled the names of the children and sorted according to minority and majority background to form two lists. These concepts were operationalized as follows: "Minority background" was defined as the child having either a family language other than French or English, or being of non-Caucasian racial background (e.g., Asian, African, Latino). 
"Majority background" included all other children. The supervisor then randomly chose one minority child from the minority list. Next, a child of matching age and gender was chosen from the majority list. This design is adapted from a study by Ogilvy, Boath, Cheyne, Jahoda, and Schaffer (1992), and permits proper, inferential conclusions and tests of statistical significance with respect to teacher perceptions of the children in centers in the three cities. No data were collected on ethnicity and background of teachers.

Family Study. Our native-speaker facilitators in the three cities convened 14 parent focus groups (total 108 parents) of different ethnocultural backgrounds to ask them about their and their children's experiences with child care centers. The parent representation was sought from new immigrant groups in each of the three designated cities. Further, we wanted to hear from established immigrant groups; these are marked in brackets for each city. The focus groups, categorized by city, represented the following ethnic and linguistic backgrounds:

Toronto: $\quad$ Spanish, Cantonese, Jamaican, Farsi, Tamil, (Greek);

Montreal: Spanish, Vietnamese, Haitian, (Portuguese);

Vancouver: Spanish, Mandarin, Somali, (Cantonese).

It is noted that the focus group data do not permit "triangulation" in the strict sense, regarding specific incidents. Since this was a preliminary study, it appeared plausible to the researchers that the number of parents and comments would be large enough to identify types of incidents and permit preliminary comparison of perspectives on some main issues facing the parents and teachers.

\section{Data Analysis}

The qualitative and quantitative data were pooled and aggregated by topic. Only the data and interpretations for the topic of teacher-family interaction are reported in the present paper. As recommended by Miles and Huberman (1994), we compared multiple perspectives, but on similar circumstances and events. As in well-known, multi-source ethnographic studies (e.g., Fine, 1990) we sought to draw upon and coordinate a variety of types of data from informants (stakeholders) in various categories or institutional roles. As part of the approach, the qualitative data were used to provide deeper insights into the circumstances depicted in the quantitative data. In the larger study, coordination of quantitative and qualitative data was intended to provide critical insights into the ordinary types of perceived problems; otherwise, critical remarks from certain parties might be dismissed as atypical or as products of the researcher's political agenda.

\section{Results}

Our four main findings as revealed by this coordination approach are now reported. Prominent in all of them is the dramatic difference between parents and teachers in perceptions of even the most minor events. Understanding these differences is an essential first step in addressing the troubled relationships we found between parents and teachers. The reader is reminded that the data do not permit the drawing of comparative conclusions about majority and minority parents. Demonstratively significant quantitative data on ethnoracial comparisons were obtained only in the Center Study minority-majority child component. The findings below should be considered as preliminary since they were derived by qualitative 
analysis of themes identified in interviews of parents, teachers, and supervisors at a number of locations. In the following section, these conventions are used for attribution of quotations: parents $(P)$, teachers $(T)$, supervisors $(S)$.

\section{Finding 1}

Although both minority parents and teachers agreed that minority parents were not involved enough in the child care setting, they disagreed about the reasons for the lack of involvement.

Attendance at meetings. A main source of frustration for the center staff was that parents reportedly did not come to scheduled meetings and did not seem to dedicate the necessary time and energy to participate in the center activities.

We go to a lot of trouble to put [family] meetings on and it's always the same few who show up. (T)

In fact, a great many of the parents agreed that they did not attend scheduled parent meetings. They mentioned linguistic barriers, lack of time, fatigue, and many meeting topics that were perceived as irrelevant to them.

Sometimes I want to make suggestions, but there is no interpreter. $(\mathrm{P})$

In my center, they send home minutes of what happened in the meeting so I understand better. (P)

The supervisor does most of the talking and usually talks about fund raising. (P)

Many parents wanted meetings in which they are asked whether they have concerns, and where interpreters are present. "When a center makes an effort to find interpreters, it shows they really care and are interested in hearing what parents have to say." Opportunities to talk to other parents were often seen as highly valuable. Parents frequently noted that because of language barriers and the rushed pace at pick-up time, they feel isolated and alone.

A few parents said they would attend a parents' meeting but were not aware if such meetings took place.

There is no parents' and teachers' meeting in our daycare. If there is a meeting about children's issues I would go. (P)

I want to come in and be involved but not to be disrespectful and seem as if I'm telling them how to run their school. Sometimes I get a notice and am not sure if I'll understand so don't go. If I was personally invited, I would come. (P)

Some parents wanted a monthly scheduled meeting where they had the opportunity to ask questions and give information. Others mentioned how they liked dropping in at various times and feeling welcome to observe, ask questions and gain information.

On the other hand, some parents wished to become more involved in the child care centers. One parent offered to do a multicultural workshop as a follow up to a racist incident, 
but the supervisor did not respond. There was a great deal of discussion of the importance of becoming more involved. Some parents said they would be interested in seeing their children performing at parent meetings (e.g., reciting poems, singing).

The general picture, from the parents' side, it appeared, was that many would like to have meaningful participation in their child's center and that they would like to discuss their child's progress with experienced teachers. Many would also like to be involved with some of the daily activities so they could learn more about the program and how their child is doing. Some parents' comments are as follows:

If I would be asked to participate or help out, why not? I can help out in educating staff about my own culture at least. $(\mathrm{P})$

In the case of celebrating Nowruz (Iranian New Year), if the staff had asked me to help them in celebrating, I wouldn't have minded helping out. Nobody asked me. I like to participate. (P)

Parents' apparent lack of interest in establishing communication. Many teachers perceived families as not eager to interact with the school personnel.

For these parents, the daycare is viewed as a baby-sitting service and they don't have much contact with the staff. They don't show up for social occasions. They pay and feel they've done their share in that way. They're not willing to listen to information/concerns about their children. They don't "hear" us. (S)

Even when we offer help, many parents are not interested to talk to us. (T)

The greatest challenge is ...to transmit the center goals and philosophy to them. (T)

The views of parents were quite different. Many said they wanted to know more about the day-to-day happenings at the center; although teachers were willing to answer parents' questions, some parents stated that they rarely volunteered information. Since teachers seemed to be so busy, many parents were reluctant to ask too many questions. When teachers did take the time to talk to parents and ask questions, this was interpreted as a sign of interest and respect. Some parents stated that teachers rarely told them about the child's day; others wanted specific daily information on eating, sleeping, and toilet routines.

I am tired of being always the one to initiate conversations and ask questions. (P)

One day, I found my son's t-shirt, soaking with blood, in his lunch box. The teachers did not even explain to me what had happened. I did not pursue this matter and just took it as a nose bleed. (P)

The teacher always smiled but when I saw her at the market, she hardly said 'hello' to us. (P)

Some parents often expressed dissatisfaction with written reports they received. Some said they did not want such reports to focus on isolated incidents but to show the teacher was following children's academic progress and knew where they were. 
Parents' apparent lack of respect for teachers. Supervisors frequently told us that many parents had been disrespectful to them:

$\mathrm{He}$ [father] has a real attitude problem in that he views women and us staff as his servants. (S)

When something arises and there is a problem with the child, the parents say the center staff is being racist. (S)

Some parents view me as the baby-sitter and have no respect. Others put me on a pedestal and think I know everything. (T)

When I first met him he [father] refused to shake hands with me and offered no explanation; I felt so insulted. (T)

In contrast with the teachers' and supervisors' perceptions, many parents expressed a great deal of respect for the teachers. Parents often stated that teachers are professionals and know what they are doing. Although many parents would like the children to spend more time reading and writing, the teachers were perceived as authority figures who know what is best for children.

The daycare centers know what the children will need when they enter elementary school. They probably have a plan on what and how much to teach to ease them into school. (P)

The kids listen to the teachers; they know how to discipline them. (P)

\section{Finding 2}

Minority parents and teachers tended to be unaware of their basic differences in ECE goals, particularly with respect to cognition, social skills, and respect for authority; they gave conflicting accounts of difficulties related to these goals.

Teacher's perception of parental understanding of program goals. Many supervisors and teachers reported that the major challenges in working with diverse populations was that the parents were not sufficiently knowledgeable about the goals of early childhood settings. For example, two teachers said:

These [minority] parents don't understand how child care functions: they think the morning snack is breakfast. (T)

I'm not always sure if parents understand the forms that are sent home.

Since the teachers in the Center Study appeared to have different perceptions about treatment of children, we had established a rigorous method capable of supplying evidence corroborative of the existence and nature of such perceived situations. We sought quantitative information for comparing majority and minority children and families. The methodology of the minority-majority child component did provide a proper basis for such comparisons. We asked the teachers a set of questions about contact with the families of these two specific children, and their responses are shown in Table 1. 
Table 1.

Amount of Contact with Families of Minority and Majority Children

\begin{tabular}{|l|c|c|}
\hline CONTACT & $\begin{array}{c}\text { MINORITYFAMILY } \\
N=199\end{array}$ & $\begin{array}{c}\text { MAJORITY FAMILY } \\
N=199\end{array}$ \\
\hline Minimal & $84(42 \%)$ & $57(29 \%)^{*}$ \\
Daily & $96(48 \%)$ & $96(48 \%)$ \\
Extensive & $19(10 \%)$ & $46(23 \%)^{* *}$ \\
\hline
\end{tabular}

${ }^{\star} p>.05 ;{ }^{* *} p>.01$

The chi-square analysis indicated significant differences between teachers' relationships with families of minority and majority children in the "extensive contact" category. Analysis by individual city revealed the same patterns as for the aggregate data. That is, parents of majority children were more likely to have in-depth conversations with teachers than were parents of minority children. These extensive contacts included discussing home issues and talking about personal problems. Families of minority children were more likely to have minimal contact with teachers than families of majority children. In sum, substantial contacts were found more in teacher-majority parent relationships; minimal contacts often marked the relationship between teachers and minority parents. The issue of family structure across majority or minority samples was not addressed, hence the degree of possible confounding influence was not determined.

To gain information about teachers' perceptions of parents' attitudes toward school programs, we asked teachers the following question: "How well do the parents understand the program?" The information is summarized in Table 2.

Table 2.

Teachers' Views of Parental Understanding of Program Goals

\begin{tabular}{|l|c|c|}
\hline $\begin{array}{c}\text { DEGREE OF } \\
\text { UNDERSTANDING }\end{array}$ & $\begin{array}{c}\text { FAMILY OF MINORITY CHILD } \\
N=199\end{array}$ & $\begin{array}{c}\text { FAMILY OF MAJORITY CHILD } \\
N=199\end{array}$ \\
\hline Very WellWell & $97(49 \%)$ & $134(66 \%)^{* *}$ \\
Adequately & $32(16 \%)$ & $11(5 \%)^{*}$ \\
Slightly & $17(9 \%)$ & $3(1 \%)^{*}$ \\
Not at All & $10(5 \%)$ & $5(3 \%)$ \\
Don't Know & $43(21 \%)$ & $46(23 \%)$ \\
\hline
\end{tabular}

${ }^{*} p>.01 ; * * p>.001$ 
Parents of majority children were significantly more likely to be perceived as understanding the program objectives than parents of minority children. Analysis by individual city revealed the same patterns as for the aggregated data. This included knowledge about daily routine, disciplining methods, desirable and undesirable behavior. It is noted that for all minority and majority children considered together, about one fifth of teachers said they did not know whether or not the family understood the program goals. In sum, teachers differentially perceived parents of minority children (compared to parents of majority children) as not understanding school program goals.

Families' perception of early childhood education goals. There is first-hand evidence from the Family Study that many parents knew little about programs. They asked facilitators questions about teacher qualifications. Many parents were surprised to find that some "teachers" were placement students and that some children had more than one teacher when they attended a half day kindergarten in addition to the child care program.

Families' goals for their children in ECE settings. In the Family Study, parents were construed by teachers as unaware of ECE goals, nonetheless, they frequently expressed goals of their own for their children in early childhood settings. Many parents articulated several concerns about program practices and socialization and believed teachers were not addressing these concerns. Many believed children should be taught good manners, how to behave at home and be obedient. Learning to get along with peers was also seen as a valuable experience. Some parents felt that the children were given too much freedom and too many choices at school, which caused problems at home.

... I expect my child to be well mannered, using her 'please' and 'thank you.' Unfortunately they don't carry on those sort of things at daycare, I guess because they're so pressed for time. (P)

What I don't like and also concerns me is many children use bad words and my daughter has learned the bad words. (P)

The teachers need to be more strict, to have rules, to emphasize order and neatness. Children need to know proper manners such as not taking things with the left hand or acting disrespectfully to relatives. (P)

Parents in the Toronto Cantonese group were unanimous in expressing their anger against a forced outdoor time in cold weather. They felt this not only led to numerous colds but also children got overheated while waiting for others to be ready. This theme was repeated numerous times in other groups, and many parents felt centers should be flexible enough to accommodate parents' wishes for their children to stay indoors.

My kid got sick from playing outside. I don't like it. Some other kids looked sick too. They come in with runny noses, cold hands and feet. It is very bad. $(P)$

When it was really cold, I didn't think they should be taking them outside because nobody can dress your kid like you can dress your kid. When the wintertime comes, my kid has scarves around here, hat down there ... (P)

When I come to pick up my kids, some kids don't have mittens ... they could get frostbite or anything. (P) 


\section{Finding 3}

Schools and minority parents appeared to have substantial differences over what constitutes proper child-rearing methods in the home. The practices of minority parents were often viewed by teachers as lax.

Teachers' views of guidance and discipline at home. Teachers felt that in many cases the children were babied, spoiled, and inappropriately raised at home.

Some parents accept soiled pants at 4 [years]; some still have bottles at 3 years. (T)

The [specific cultural group] boys are so pampered [at home] and here they have to clean up just like everyone else. They're confused with such different expectations. ( $T$ )

Parents don't understand the way things are done in Canada and it's hard to get the concepts across to them. (T)

Parents frequently did not seem to be aware of the teachers' perceptions. It seems the agenda of the teachers had not been expressed to them but was being used implicitly in assessing the approaches of the parents.

Teachers' views of child-rearing methods at home. Many (32\%) of the teachers reported significant home-school differences in child-rearing that made it difficult for them to work with minority families and children. Many teachers felt that parents did not understand Canadian ways or were unwilling to adopt Canadian and child care center practices.

Disagreements between family values and expectations and those of the school were frequently cited. Disagreements cited included difficulty understanding parents' philosophies. Some families had practices that were perceived as non-hygienic; teachers said they did not understand Canadian ways. There were differences in upbringing between home and school.

One child did not wear underwear; it was so disgusting. (T)

They don't dress the children appropriately for winter; other times they put too much clothing and the poor kids are boiling. (T)

Parents' views of home practices. Of course we did not ask parents if they were spoiling their children or providing proper child rearing. The reports of the facilitators indicated that generally, the parents, like majority parents, viewed themselves as working hard to provide appropriate care. Many parents seemed, to the facilitators, to be trying to do the specific things that would be helpful to that child within that cultural frame of reference.

In Afghanistan, we have a belief that to make a child's eyesight stronger, we use sorma [similar to eye pencil]. I had put sorma in my son's eye and one of the teachers laughed and made fun of my son by saying, "You have put eye pencil in your eyes" [sarcastically]. (P)

Clearly, the mother's reasons for this practice did not make sense to the other children or teachers, and so she felt her child rearing methods were being dismissed and even ridiculed.

Further, the fact that many parents wanted to visit the school and be more involved suggests they felt competent about child-rearing methods. Their critique of practices at 
school demonstrates they felt more concerned and knowledgeable about child-rearing methods than the teachers may have realized.

\section{Finding 4}

Based on teachers' and parents' reports, racial and discriminatory incidents, according to the various definitions of those involved, were not uncommon in child care centers; sometimes teachers were unaware of them. Subtle and unintended effects of racism were much more noticed by some parents than by many teachers.

Nature and frequency of incidents. Teachers were asked to describe any incidents among the children that seem to reflect negative racial stereotypes. We asked participants to describe racist incidents they had witnessed. Since no definition of racism was proposed to participants, they were permitted to work with their own understanding of the concept. Since many investigators agree in emphasizing the subjective experiential effects of racism, we felt it appropriate not to impose what we outsiders would consider or hypothesize to be racially based incidents. There are a number of definitions of racism, and the examples we heard fell into the categories of negative comments and physical avoidance or exclusion. In the following data, analysis by individual city revealed the same patterns as for the aggregate data.

Forty-six percent of teachers (91/199) at diverse centers with an average of seven years of experience in the ECE field reported they had never, during their ECE careers, seen what they would describe as a racial or discriminatory incident between children. Further, they thought such incidents were unlikely, if not impossible, in this age group (three to six). Such incidents were, however, perceived to be more likely in school-aged children. A typical statement is given below:

In six years that I have worked here we have never had a discriminatory or racial incident. ( $\mathrm{T}$ )

The 54\% of teachers who had seen racial incidents during their ECE careers reported a total of 122 incidents among the children, as shown in Table 3.

Table 3.

Types of Incidents Observed Among Children

\begin{tabular}{|l|c|}
\hline \multicolumn{1}{|c|}{ INCIDENTS } & TOTAL $(N=122)$ \\
\hline Verbal Behavior & $55(45 \%)$ \\
Avoidance/Exclusion & $34(28 \%)$ \\
Attribution of Stereotyped Roles & $19(16 \%)$ \\
\hline
\end{tabular}

It would be useful in interpreting the caregivers' perceptions to know their "race" or self-ascription of such. Direct data would have been ideal. Such data were not collected because it would have seemed intrusive and we were trying to establish rapport with them. However, several US investigators have reported that a vast majority of pre-service teachers 
are of white, middle-class background (Fuller, 1992; Zimpher \& Ashburn, 1992). Canada has a lower proportion of visible minority persons in its population (estimated at 13\%, Census of Canada, 1991) than does the US and the employment patterns are generally similar.

The incidents named were mostly evident rather than subtle. Derogatory name-calling between children was the most frequently observed response $(45 \%)$. This included making fun of physical features such as hair, skin, smell, accent, and cultural origin. Avoidance and exclusion incidents were very common: instances where children refused to touch or sit next to a child of a different racial background were observed in 34 of 122 cases (28\%). Children would often attribute culturally stereotyped roles to each other. They said:

He [Asian child] looks ridiculous; look at the way his mother carries him.

All Black children are poor.

You can't be the boss, you're Black.

Because some parents had suggested that teachers were not fully sensitive to the importance of racial issues, the investigators had decided to probe beyond intentions and self-reported sentiments to ask teachers what they did in situations that the teachers themselves defined as racial. Teachers were also asked how they handled the situations and who was involved; their responses are summarized in Table 4.

\section{Table 4.}

Teachers' Response to Racial Incidents

\begin{tabular}{|l|c|}
\hline \multicolumn{1}{|c|}{ ACTIONS CITED } & TOTAL $(N=122)$ \\
\hline Talk to Children Involved & $87(71 \%)$ \\
Do Nothing & $20(16 \%)$ \\
Conduct Group Discussion & $17(14 \%)$ \\
Involve Families & $15(12 \%)$ \\
Consult Colleagues & $7(6 \%)$ \\
Document Incident & $5(4 \%)$ \\
\hline
\end{tabular}

Our categorization for those who did nothing included teachers who said there was no need to act, those who told the children all people are nice, and those who believed modeling good behavior was sufficient response. These teachers said that since the children did not intend to hurt others and often did not know what they were saying, there were no racial elements.

The vast majority of the teachers (84\%) who witnessed racial incidents, however, did something in response. The most common response $(71 \%)$ was to talk positively to children and to encourage children to talk to each other. Most commonly, the staff person approached the problem individually and talked to the children involved. Only $6 \%$ reported seeking other staff and only $12 \%$ involved children's families. Generally, the incident was not dealt with collectively since only $14 \%$ spoke of using this as a learning opportunity with the rest 
of the children. In most cases, interaction was limited to the two children involved. Only 5 of the 122 teachers said they had documented the incidents through a serious occurrence report, and one center out of 77 worked to develop a policy following an incident. How teachers deal with-or are perceived to deal with or avoid-racial incidents was a concern expressed by some parents in the focus groups (see below) and most often they felt unable directly to request appropriate review by school personnel, for these types of incidents.

Parents' views of racial issues. Parents in focus groups were specifically asked about incidents involving race, language, or cultural bias. Some parents did not consider issues of race to be relevant to them. For example in Toronto, several Spanish and Cantonese parents said racism applied only to Blacks.

Several participants recounted their children's involvement in incidents with racial overtones. One mother told of her attempt to follow up on an incident when her child was called "a nigger" by another child. When she called the school to tell them, the supervisor got upset and said she was accusing them of being racist. The matter was never resolved, as it was not clear who said what to whom.

A second mother had a similar experience. Her child got angry at home and said "Stop that, Blacky." The child reported hearing this at school, but the teacher said she had never heard it, not from children this age. The mother took her concern to the supervisor, and after three weeks, the supervisor called to apologize for not believing her and to say they had found out who was making these remarks.

So I [same mother] say, well you need to deal with this right now ... So they went through a little racisms ... you know ... they talk to the kids about how everyone is supposed to play together and all that. I even said I would come in to talk to them, but they said they had already handled it. (P)

There was a sense among some minority parents that if they complained about anything, this would have repercussions for the child. In one case, the child told the mother he had been slapped by a teacher; the school denied it to the mother.

... so I said [to the supervisor] if he said it happened then it happened. So she said nobody hit him. And he's the best kid in the daycare and he doesn't give no trouble ... So it was left there but deep down inside I was not comfortable ... I don't want him to suffer the consequences after all this ... So I let it go. (P)

Besides examining overt incidents, an assessment of racism necessarily involves identifying more subtle practices that may be present. Unthinking and usually non-hostile actions or omissions may indicate something about the presence of structural supports for racism. By that phrase, we direct attention to institutional privileging of white or European thought patterns and values over those of the rest of the world. Some parents spoke as follows:

When the white mothers tell staff their child had an accident, they change the child immediately; when my child is wet, they tell me to change her. 
What really concerns me is I feel I'm ignored by the staff. I will give you an example: If I' $m$ with another parent, the staff will pay attention to the white parent and not me. $(\mathrm{P})$

The staff do not have any knowledge about my language, race or culture. That is why I feel they ignored me. What I know [is] that the staff don't have enough knowledge about my culture. I have not seen them handling any case [well]. Teachers should learn how to be sensitive to other people's culture or race. Some of them are sensitive and some are very ignorant. (P)

\section{Discussion}

\section{Issues of Communication, Involvement, and Respect}

The troubled relationship between teachers and parents exists in a particular, structured ECE system whose routine processes lead to a number of misunderstandings and miscommunications among stakeholders. The data show large areas of agreement about particular objective details: parents not going to meetings, teachers and parents not talking much to each other. Both parents and teachers had feelings of being neglected and considered themselves to be in a disempowered or marginalized position.

Parents, besides desiring to hear the teachers talk about their children, often spoke of wanting teachers to listen to them and appreciate their views and cultures. Similarly, many teachers wanted parents to demonstrate their interest by inquiring about program goals and participating in program activities. Holloway and her colleagues' (1995) findings are helpful in raising questions about the present teachers' reports of lack of parental interest. The participants were found to "[place] great importance on preparing their children for school" (p. 462). Thus we ask if the teachers, despite good intentions were routinely failing to perceive - or perhaps to understand—signs of parent interest.

We have earlier described the institutional factors that affect parents' relationships with the ECE system and providers (Fein, 1980). We have made the proposal that the standard model of ECE places administrators and teachers in an expert position regarding child rearing. The present findings regarding teachers' views and parents' experiences are consistent with the views of Lubeck (1994) and Walsh (1991) that North American centers by and large follow a standard model. The model suggests a possible account for much of the present data: The teachers' lack of contact with the parents is not simply due to busyness but likely reflects an assumption that experts need not continuously consult those whom they are helping in professional interventions. That the teachers did not "hear" the parents or realize what their values were is thus, arguably, an outcome of the routine, institutional process of the present ECE system. Likewise, the parents' experience of not being listened to does not reflect ill intention on the part of the teachers, but-if we follow Gonzalez-Mena's (1997) argument-the parents' subordinate and marginalized position within the system.

Further, our findings are consistent with the earlier proposal that many professionals in the ECE system work according to assumed universal patterns of child development. There were many reports of differences between teachers and families regarding what children are able to do at certain ages, the type of appropriate discipline at each age, and what families 
should do to support development. We suggest a link between the goal of routinized institutional functioning and the universalistic assumptions of child care personnel about developmental patterns. Further, routine pressures on teachers demand elaboration of rules of thumb, and "handy" generalizations across cultural groups.

Although all parties in the ECE system are responsible for constructive collaboration, we believe that the primary responsibility lies with the professionals: the teachers and center supervisors. This position is in accord with that of the National Association for the Education of Young Children's (NAEYC) Guidelines for Developmentally Appropriate Practice which stated that "Teachers are responsible for establishing and maintaining frequent contacts with families ..." (Bredekamp, 1987, p. 12). There is every indication from the present data that many, if not most, parents would respond constructively to such initiatives (see also Chang, Muckelroy, \& Pulido-Tobiassen, 1996).

A key question is: Since the teachers had a duty to involve parents and at some level were well disposed toward parent involvement, what explains the absence of interactions in which parents and teachers meet and listen to each others' concerns? The situation is arguably due to institutional hindrances rather than ill-intentioned actions of individuals. Where there are few or inadequate mechanisms for involving parents and eliciting their input, the type of dysfunction we have described is likely to occur, particularly in diverse settings. Further, the centers' adherence to a standard model results in teacher-parent meetings and conferences with one-way agendas in which parents are powerless. Parents are expected to come and receive what is offered. Parents will not be able to effect changes unless structures are set up for two-way interactions for both sides to listen and talk, unless parents have some power to ensure their ideas are implemented. A key component of establishing a collaborative model is the development of an understanding of families' cultures and concerns, and of obtaining practical experience in working with parents. We found numerous instances where the values of the home and school clashed in significant ways (similar events are reported in Gonzalez-Mena, 1993; Heath, 1982). Institutional mechanisms for parent participation can help prevent or resolve such conflict. Several investigations have shown that programs involving parent participation led to significant input and interest (e.g., Delgado-Gaitan, 1990). New structures are needed to provide for true involvement of all parties.

\section{Goals of Early Childhood Education}

Many parents wanted the teachers to focus on more didactics, values, and manners. With hindsight, the question of to what degree parents understood program goals presupposed a common agenda. Teachers' frequent reports about little understanding of program goals can also be understood as lack of parental endorsement of official goals. Perhaps teachers did not recognize that parents had goals of their own. Our findings here are consistent with those of Holloway et al. (1995) in that parents appeared not to accept child-focused orientations and believed that teachers should help teach respect for adults.

The Latina mothers in our sample, from their vantage point based on traditional beliefs of their home culture, expressed concern about the disrespectful attitude North American children frequently display toward adults. (Holloway et al., 1995, p. 466) 
Our suggestion for dealing with this problem is stated best by Holloway et al.

... there is much to be gained by seasoning professional knowledge about effective pedagogies with respectful consideration of parents' cultural models of child rearing and education. (p. 470)

The NAEYC position statement on linguistic and cultural diversity (1995) clearly states the ideal goal of complementary practices between home and school but also acknowledges how cultural clashes may occur.

Partnerships between the home and the early childhood setting must be developed to ensure that practices of the home and expectations of the program are complementary. (p. 9)

"Cultural clashes"... often loom larger than need be because lines of communication may not exist. (p. 15)

That cultural clashes exist is supported by the findings of the present study. In order to help alleviate such clashes, teacher candidates need to be prepared in ECE programs to learn that there is no simple resolution of cultural differences; that unthinking enforcement of mainstream values can no longer work. There are possibilities for mutual accommodation between ECE teachers and parents of ethnoculturally diverse children. It is submitted here that establishing communication is critical. In a majority of the cases, we believe some sort of arrangement can be worked which honors the main priorities of all stakeholders.

\section{Issues of Race}

Because of the degree of accord between parent and teacher reports, there does appear to be a continuing problem of racial incidents irrespective of the good will of center staff. Our first caveat: It is to be emphasized that the category of racial incidents is itself open to question. The problem here is not academic hair-splitting but is reflected in reports of parents of different racial and cultural backgrounds: Several Asian parents thought they faced discrimination problems, but not racial discrimination. A second caveat: Minority parents or even those of a specific group (e.g., African-Canadian) are not homogeneous for purposes of this analysis. For instance, we talked more to African-Canadian mothers than to fathers, and hence the picture we present should not be considered to be based solely on racial differences per se. The minority parents were mostly women and came from a number of different classes and castes.

Having decided to call some problems racial, we shall now discuss the finding that the significance or gravity of "racial incidents" was assessed differently by teachers and parents. In our investigation many teachers stated their belief that racial issues were being adequately handled so there was no need for outside intervention. Such reports are entirely consistent with the standard or expert model according to which parents are not involved nor even told of ordinary incidents. Thus routine institutional processes, we suggest, more than individual teacher bias, probably account for some parents' feelings that their questions about racial incidents were not welcome. Parents, in fact, would appreciate being asked for input because they believe they have a much clearer sense of the impact of the incidents on their children and a greater experience, arising out of their community experience, in dealing with racism. 
There is no evidence here to suggest that the teachers saw racist incidents, in their own perception, as having implications regarding ECE institutional practice. The parents, on the other hand, showed some awareness of such issues. Some minority parents, for instance, reported that the teachers spoke to them less than to the parents of white children, and we believe that these parents may have been aware of these incidents as common outcroppings of routine, seemingly impersonal institutional processes.

Within child care centers, how parents and teachers interact over racial issues is influenced by two sets of variables: first, each party's beliefs about what is happening between the children; second, the dynamic of the adult-adult interaction itself, which inevitably has a racial aspect. The adults' encounter is shaped by the respective positions of the racial groups with which they identify themselves and one another. Thus we propose (see Troyna, 1992) that the issues of institutional and individual racism should be addressed at several levels: teacher-child, child-child, teacher-parent. Louise Derman-Sparks (1991), besides her useful analysis, has provided a number of useful suggestions for anti-bias approaches for various stakeholders within ECE programs (see also Corson, 1994; Municipality of Metropolitan Toronto Children's Services, 1995; Ontario Ministry of Education and Training, 1994).

Because institutional issues need to be addressed, we would stress the need for courses in racism to help teachers-and teacher candidates-learn about structural disadvantage, not merely overt signs. A social justice perspective is essential (Cummins, 1989; Darder, 1991; Sleeter \& Grant, 1987). We believe that the evidence cited here shows the need for a proactive reform for ECE teacher preparation, and an equally proactive restructuring of institutional policies and practices. Within new structures, new relationships may evolve for the benefit of children, families, and teachers.

\section{Limitations}

Despite the large number of informants in all stakeholder positions, the design in two of the studies (Center Study, Supervisor and Teacher Interview component; and Family Study) did not allow definitive and direct minority-majority comparisons. The study of teachers and minority children would be enhanced if further studies included comparison groups and direct observations. The data, except for the second component of the Center Study (minoritymajority child pairs), are in respect to types of incidents in a variety of settings. Coordination of multiple perspectives and attitudes in the present study permits only preliminary conclusions, which require testing in follow-up, especially case studies focusing on exactly the same incidents. We underscore the fact that the proportions we found generally do not allow inference about proportions in the ECE community at large. Specific quantitative conclusions cannot be drawn from the presented data, considered on their own. Further, the present qualitative findings, considered on their own, do not license generalization to the larger population of children in centers, their parents, and their teachers.

\section{Conclusion}

Early childhood education in ethnoculturally diverse settings faces a number of difficulties which we have highlighted in the reported data. It is also true that teachers and parents spoke of being able to interact successfully for the benefit of the children on many occasions. Notwithstanding the many areas requiring improvement, it was rare for either parents or 
teachers to question the integrity of the system or to completely disparage the other party. Both stakeholders want to work through their difficulties, and we believe in their ability ultimately to do so. What is to be done? We propose, in parallel with NAEYC (1995) and the Royal Commission on Learning (1994) that a more collaborative model for ECE be adopted. We suggest that such a model would improve communication and problem solving and ensure that attempts to honor diversity go beyond words and become realized in practice. The model offers one way for parents to become valued partners in children's education. It would also be easier for both stakeholders to remain conscious of the fact that they both care deeply about the children, and all are acting for the best as they see it. We continue to believe that, with adequate time, resources and an abundance of commitment, genuine change is possible.

\section{References}

Bauch, P. A. (1992, April). Toward an ecological perspective on school choice. Paper presented at the annual meeting of the American Educational Research Association, San Francisco. (ERIC Document Reproduction Service No. ED 346 595)

Becher, R. M. (1985). Parent involvement: A review of research and principles of successful practice. In L. G. Katz (Ed.), Current topics in early childhood education, 6, Norwood, NJ: Ablex.

Bernhard, J. K. (1995). The changing field of child development: Cultural diversity and the professional training of early childhood educators. Canadian Journal of Education, 20 (4), 415-436.

Bernhard, J. K., \& Freire, M. (1996). Latino refugee children in child care: A study of parents and caregivers. Canadian Journal of Research in Early Childhood Education, 5(1), 59-71.

Bernhard, J. K., Lefebvre, M. L., Chud, G., \& Lange, R. (1997). The preparation of early childhood educators in three Canadian areas of immigrant influx: Diversity issues. Canadian Children, 22 (1), 26-34.

Boston, K. (1995). NSW Department of School Education priorities. Sydney, Australia: New South Wales Department of School Education.

Bredekamp, S. (1987). Developmentally appropriate practice in early childhood programs serving children from birth through age eight. Washington, DC: National Association for the Education of Young Children.

Bright, J., Hidalgo, N., Siu, S., \& and Swap, S. (1994, April). Home school connections with parents from diverse backgrounds in kindergarten and first grade. Paper presented at the annual meeting of the American Educational Research Association, New Orleans.

Census of Canada (1991). Ethnic origin (Catalogue \# 93-315, Table 2B).

Chang, H. (1993). Affirming children's roots: Cultural and linguistic diversity in early care and education. San Francisco: California Tomorrow.

Chang, H., Muckelroy, A., \& Pulido-Tobiassen, D. (1996). Looking in, looking out: Redefining child care and early education in a diverse society. San Francisco: California Tomorrow.

Corson, P. (1994). Anti-bias curriculum in early childhood education: At the nexus between home and school. Orbit, 25(2), 39-40. 
Costas, M. (1991). Hispanic parental involvement. M.S. Practicum, Nova University. (ERIC Document Reproduction Service No. ED 339 462)

Crooks, C. R. (1970). The effects of an interracial preschool program upon racial preference, knowledge of racial differences, and racial identity. Journal of Social Issues, 26, 137-143.

Cummins, J. (1989). Empowering minority students. Sacramento: California Association for Bilingual Education.

Darder, A. (1991). Culture and power in the classroom: A critical foundation for bicultural education. Toronto: OISE Press.

Delgado-Gaitan, C. (1990). Literacy for empowerment: The role of parents in children's education. London: Falmer.

Derman-Sparks, L., \& the ABC Task Force (1991). Anti-bias curriculum: Tools for empowering young children. Washington, DC: National Association for the Education of Young Children.

Drolet, C. (1994). S'adapter à la diversité: Faits saillants d'une enquéte sur la diversité ethnoculturelle les service de garde en garderie et en milieu familial et dans les agences de la région de Montréal. Petit à petit, 12(6), 8-10.

Endsley, R. C., \& Minish, P. A. (1991). Parent-staff communication in day care centers during morning and afternoon transitions. Early Childhood Research Quarterly, 6, 119-135.

Fein, G. G. (1980). The informed parent. Advances in Early Education and Day Care, I, 155-185.

Fine, M. (1990). Framing dropouts. Albany: State University of New York Press.

Fuller, M. L. (1992). Monocultural teachers and multicultural students: A demographic clash. Teacher Education, 4(2), 269-277.

Ghazvini, A. S., \& Readdick, C. A. (1994). Parent-caregiver communication and quality of care in diverse child care settings. Early Childhood Research Quarterly, 9, 207-222.

Goldenberg, C. (1993). The home-school connection in bilingual education. In B. Arias \& U. Cassanova (Eds.), Bilingual education: Politics, practice, and research (pp. 225250). Chicago, IL: National Society for the Study of Education.

Gonzalez-Mena, J. (1997). Multicultural issues in child care, Mountain View, CA: Mayfield.

Hall, S. (1980). Race, articulation, and societies structured in dominance. In Sociological theories: Race and colonialism (pp. 305-345). Paris: UNESCO.

Heath, S. B. (1982). Questioning at home and at school: A comparative study. In G. Spindler (Ed.), Doing the ethnography of schooling (pp. 102-131). New York: Holt, Rinehart, and Winston.

Holloway, S. D., Rambaud, M. F., Fuller, B., \& Eggers-Piérola, C. (1995). What is "appropriate practice" at home and in child care? Low-income mothers' views on preparing their children for school. Early Childhood Education Quarterly, 10, 451-473.

James, C. E. (1994). I don't want to talk about it: Silencing students in today's classrooms. Orbit, 25(2), 26-29.

James, C. E. (1995). Toward a new response. Unpublished document, The Municipality of Metropolitan Toronto Children's Services Division. 
Johnson, E. G. (1977). The development of color knowledge in preschool children. Child Development, 48, 308-311.

Jordan, W. D. (1968). White over black: American attitudes toward the Negro, 1550-1812. Baltimore, MD: Penguin.

Kessen, W. (1983). The child and other cultural inventions. In F. S. Kessel \& A. W. Siegel (Eds.), The child and other cultural inventions (pp. 26-47). New York: Praeger.

Kessler, S., \& Swadener, B. B. (1992). Reconceptualizing the early childhood curriculum: Beginning the dialogue. New York: Teachers' College Press.

LaGrange, A., Clark, D., \& Munroe, E. (1994). Culturally sensitive child care: The Alberta study. Calgary: Alberta Citizenship and Heritage Secretariat.

Lubeck, S. (1994). The politics of developmentally appropriate practice: Exploring issues of culture, class, and curriculum. In B. L. Mallory \& R. S. New (Eds.) Diversity and developmentally appropriate practice: Challenges for early childhood education (pp. 17-43). New York: Teachers College Press.

Mallory, B. L., \& New, R. S. (1994). Diversity and developmentally appropriate practice: Challenges for early childhood education. New York: Teachers College Press.

Marques, R. (1995, April). The impact of legislation on families in Portuguese schools. Paper presented at the annual meeting of the Center on Families, Communities, Schools, and Children's Learning, San Francisco.

Miles, M. B., \& Huberman, A. M. (1994), Qualitative data analysis: A new sourcebook of methods. Berkeley, CA: Sage.

Miles, R. (1989). Racism. London: Routledge.

Municipality of Metropolitan Toronto Children's Services. (1995). The handling of racial incidents in child care programs. Unpublished document, Toronto.

National Association for the Education of Young Children. (1995). NAEYC position statement. Responding to linguistic and cultural diversity: Recommendations for effective early childhood education. Young Children, 4-16.

$\mathrm{Ng}$, R. (1993). Racism, sexism, and nation building in Canada. In C. McCarthy \& W. Crichlow (Eds.), Race, identity and representation in education (pp. 50-59). New York: Routledge.

Office des services de garde à l'enfance (1994). Enquete sur la diversité ethnoculturelle dans les services de garde en garderie et en milieu familial, et dans les agences de la région de Montréal. Montréal: Author, Direction des communications de la recherche et du développement, Gouvernement du Québec.

Ogilvy, C. M., Boath, E. H., Cheyne, W. M., Jahoda, G., \& Schaffer, H. R. (1992). Staff-child interaction in multi-ethnic nursery schools. British Journal of Developmental Psychology, 10, 85-97.

Okagaki, L., \& Sternberg, R. J. (1993). Parental beliefs and children's school performance. Child Development, 64, 36-56.

Ontario Ministry of Education and Training. (1994). For the love of learning: Report of the Royal Commission on Learning. Toronto: Queen's Printer for Ontario. 
Pence, A., \& Goelman, H. (1987). Silent partners: Parents of children in three types of day care. Early Childhood Research Quarterly, 2, 103-118.

Ramirez, J. D., \& Douglas, D. (1989). Language minority parents and the school: Can homeschool partnerships increase student access? (ERIC Document Reproduction Service No. ED 349349)

Robinson, H. B., Robinson, N. W., Wolins, M., Bronfenbrenner, U., \& Richmond, J. B. (1973). Early child care in the United States of America. New York: Gordon \& Breach.

Royal Commission on Learning. (1994). For the love of learning: Report on the Royal Commission on Learning. Torontọ: Queen's Printer for Ontario.

Sjolund, A. (1973). Day care institutions and children's development. Lexington, MA: Heath.

Sleeter, C. E. (1992). Resisting racial awareness: How teachers understand the social order from their racial, gender, and social class locations. Educational Foundations, 3, 7-32.

Sleeter, C. E., \& Grant, C. A. (1987). An analysis of multicultural education in the United States. Harvard Educational Review, 57, 421-444.

Troyna, B. (1992). Can you see the join? An historical analysis of multicultural and anti-racist education policies. In D. Gill, B. Mayor, \& M. Blair (Eds.), Racism and education: Structures and strategies. London: Sage.

Verlot, M. (1995, April). School policy improvement and the connection with the local community: The Flemish experience. Paper presented at the annual meeting of the Center on Families, Communities, Schools, and Children's Learning, San Francisco.

Walsh, D. J. (1991). Extending the discourse on developmental appropriateness: A developmental perspective. Early Education and Development, 2(2), 109-119.

West, J., Hausken, E. G., \& Collins, M. (1993). Readiness for kindergarten: Parent and teacher beliefs. (National Center for Education Statistics Report No. 93-257). Washington, DC: U.S. Department of Education, Office of Educational Research and Improvement.

Williams-Shreve, T. (1992). Parent views on race relations in child care programs. Unpublished document, The Congress of Black Women of Canada, Toronto Chapter.

Zimpher, N. L., \& Ashburn, E. A. (1992). Countering parochialism in teacher candidates. In M. D. Dilworth (Ed.), Diversity in teacher education: New expectations (pp. 40-59). San Francisco: Jossey-Bass.

Funding for this project was obtained from the Child Care Initiatives Fund Program, Human Resources Development Canada and Ryerson Polytechnic University and is based on data presented in Paths to Equity (York Lanes Press). We are grateful to the families, teachers and supervisors who adjusted their busy schedules to accommodate our interviews. For facilitating data collection we thank Chantal Drolet (Office des Services de Garde du Québec à Montréal), Brenda Patterson (Metropolitan Toronto Children's Services), Suparna Nirdosh (Ryerson Polytechnic University), Ruth Fahlman and Leslie Richardson (Early Childhood Multicultural Services). Special thanks to two blind reviewers and our colleagues who gave valuable suggestions on drafts: Harold White, Denese Coulbeck, Hedy Nai-Lin Chang, Jim Cummins, Carl James, John Lord, Arlene Stairs, Janet Gonzalez-Mena and Loujse Derman-Sparks. 